\title{
ARTIFICIAL NEURAL NETWORKS FOR THE CLASSIFICATION OF SHRIMP FARM FROM SATELLITE IMAGERY
}

\author{
Ilada AROONSRI ${ }^{1}$, Satith SANGPRADID ${ }^{2}$ (D)
}

DOI: 10.21163/GT_2021.162.12

\begin{abstract}
:
Shrimp production was the high demand for the popular in the global market in Thailand. The change of land use is important for the management and monitoring of land use changed. The objectives of this paper to (1) classification of shrimp farm using artificial neural networks (ANN) technique from the Sentinel-2 imagery. (2) change detection of land use changes map among 2015, 2018, and 2020. The land use classification based on ANN technique and the accuracy assessment by used the confusion matrices and kappa coefficient. The classify of land use classes divide into built-up, forest, water bodies, paddy field, shrimp farm, and field crop. The change detection methods used was the image differencing technique was performed to the land use changes map. The result of land use classification show that the field crop area was $80 \%$ cover the most area. The result of land use changed show that built-up, paddy field, and shrimp farm increased throughout between year 2015 to 2020. The shrimp farm between year 2015 to 2020 to increasing trend of related with the shrimp production was the high demand for the popular in the global market.
\end{abstract}

Key-words: Sentinel-2 imagery, Supervise classification, Land use change detection, artificial neural networks $(A N N)$.

\section{INTRODUCTION}

Nowadays, shrimp farming in Thailand has been cultivating shrimp for domestic consumption and exports for a long time over the past 20 years. In the year 2020, the exports of production from shrimp farming are expected to increase to 350,000 tonnes (Thai Shrimp Association, 2019). Shrimp production was the high demand for the popular in the global market in Thailand. According to the shrimp is the most popular food consumed due to the reasons the farmers changed an agricultural area into the shrimp farming. The rapid change from agriculture to shrimp farming should be an issue associated with land degradation and water pollution. Therefore, it is necessary to plan and manage environmental impacts and social conflicts that have occurred in the area. The shrimp farming mapping is important for monitoring the land use changed in these areas.

The study of land utilization is very importance for managing dynamics for land use and demand of the population (Yaday et al., 2010). Planning and managing the change of land use in the area is the first priority for future land use planning to resource and sustainable development process.

\footnotetext{
${ }^{1}$ Department of Business Digital, Faculty of Management Sceinces, Valaya Alongkorn Rajabhat University Under the Royal Patronage, 1, Moo 10, Klong 1, Klong Luang, Pathum Thani 13180, Thailand; E-mail: ilada@vru.ac.th

${ }^{2}$ Research unit of Geo-informatics for Local Development and Department of Geoinformatics, Faculty of Informatics, Mahasarakham University, Kantarawichai District, Maha Sarakham 44150, Thailand; E-mail: satith.s@msu.ac.th
} 
Currently, the geo-informatics technology has been applied for the land use changed by used the processed from the satellite images. It has been very useful to classified the land use mapping for the monitor and analyze of land use in the area (Jomsrekrayom et al., 2021; Pradabmook \& Laosuwan, 2021). Satellite Imagery an important in the sustainable development of shrimp aquaculture by providing information about land use/land cover, water quality, and coastal infrastructure (Rajitha et al., 2007). Satellite imagery has been used to monitoring areas of shrimp aquaculture, as well as to classify of land use change related aquaculture or specifically of land use in an area. Satellite imagery can support both of small and large-scale mapping of aquaculture for a better understanding and management and improve the quantifying of fish and shrimp ponds and associated production volumes to ensure comparable statistics between countries and regions (Ottinger et al, 2017; Stiller et al., 2019).

There several techniques for land use classification from satellite imagery based on supervised classification method such as parallelepiped, minimum distance, maximum likelihood, and mahalanobis distance. The maximum likelihood technique is the most popular for classify the land cover in coastal landscapes and classify of shrimp aquaculture (Alonso-Perez et al., 2003). However, the classifier method based rely upon field severing to collect the data or visual interpretation to identify shrimp pond shape samples as inputs of models (Dorber et al., 2020). The maximum likelihood technique assigned a class of land used based on the probability that a pixel belonging to a particular class that a normally distributed dataset exists, and that the statistical parameters. The classification accuracy of the maximum likelihood technique depending on the training samples are then used to train the classifier to classify the spectral data into a thematic map (Du \& Wang, 2007). Machine learning is an emerging advanced classification methodology with supervised classification methods, such as random forest (RF), support vector machine (SVM), and artificial neural networks (ANN), there are can perform better than traditional classification method (Erbek et al., 2004; Maung \& Sasaki, 2021).

Recently, machine learning methods have been used widely in satellite imagery to classify land use classification, monitoring, land use change detection, and prediction of land use change. The supervised machine learning classifier such as RF, SVM, and decision tree (DT) (Toosi et al., 2019; Ahmad, 2013; Ge et al., 2020). Currently, the application of Sentinel-2 has used widely in generally for land use monitoring (Urban et al., 2021; Migas-Mazur et al., 2021; Punalekar et al., 2021), precision agriculture (Santaga et al., 2021), fire monitoring (Kovacs, 2019; Vanderhoof et al., 2021), drought assessment (Varghese et al., 2021) and maritime monitoring (Costantino et al., 2020). In addition, Sentinel-2 has been spatial resolution varies from $10 \mathrm{~m}$ to $60 \mathrm{~m}$ and temporal resolution are only available every 5 days. In this paper, focused on ANN technique was used widely to classify the satellite image data to accuracies higher than of the tradition classification techniques (Foody et al., 1995; Toshniwal, 2005; Mahmon \& Yaacob, 2014. The objective of this paper to (1) classification of shrimp farm using ANN technique from the Sentinel-2 imagery. (2) change detection of land use changes map among 2015, 2018, and 2020.

\section{MATERIALS AND METHODS}

\subsection{Study area and data collection}

This study was conducted at Yang Talad district, Kalasin province, Thailand (Fig. 1). The study area has tropical monsoon weather and the average temperature ranges from 26.9 - 28.2 degrees Celsius. The study are lies between $16.28^{\circ}$ to $16.60^{\circ} \mathrm{N}$ Latitude and $103.15^{\circ}$ to $103.50^{\circ} \mathrm{E}$ Longitude.

Sentinel-2 Imagery is a European wide-swath, high-resolution, multi-spectral imaging mission. The spectral resolution of Sentinel-2 imagery shown in Table. 1 (USGS EROS Center,2015). 


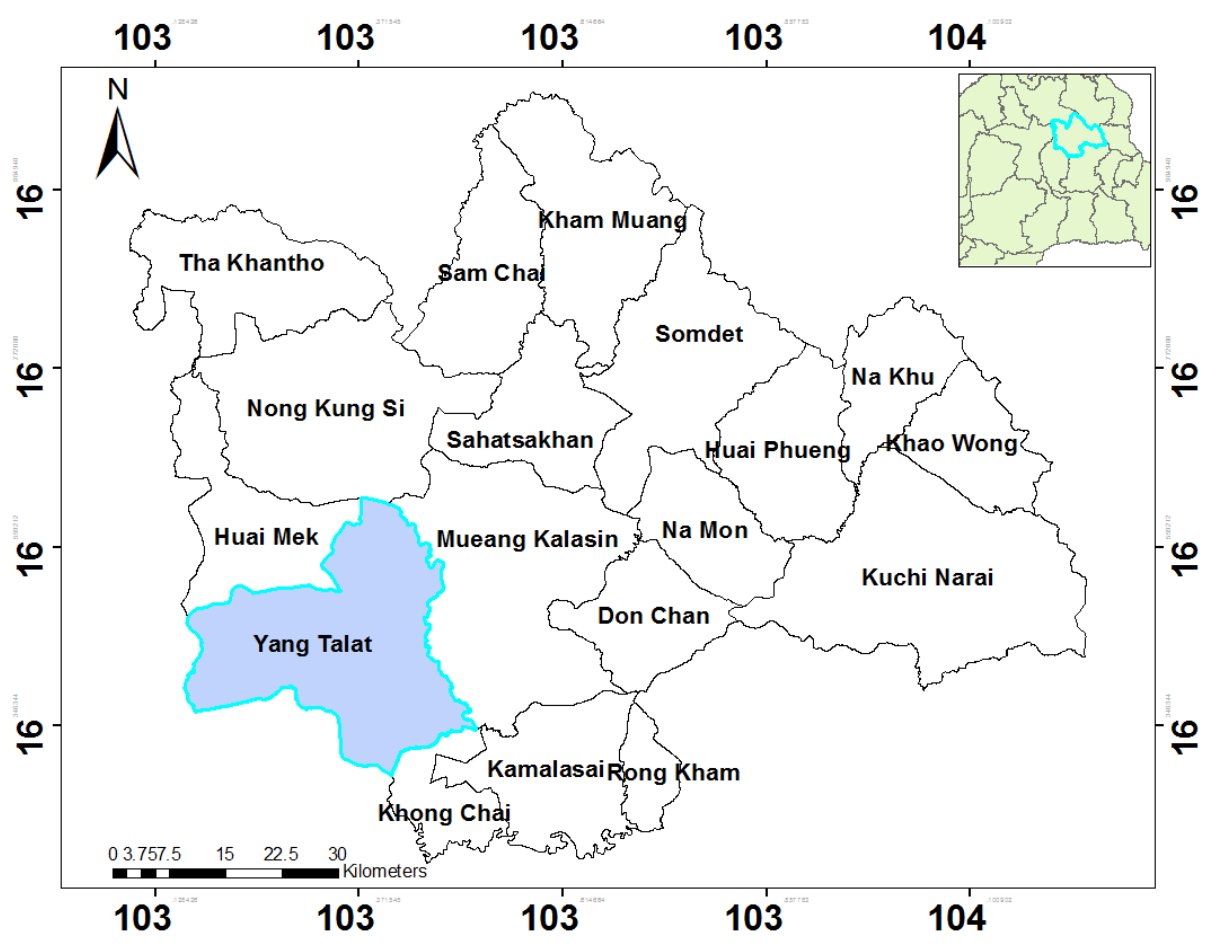

Fig. 1. Study area.

Table. 1

Characteristics of the Sentinel-2 Imagery.

\begin{tabular}{|c|c|c|c|c|c|}
\hline \multirow{4}{*}{$\begin{array}{c}\text { Spatial resolution } \\
(\mathbf{m})\end{array}$} & $\begin{array}{c}\text { Band } \\
\text { Number }\end{array}$ & $\begin{array}{c}\text { Central } \\
\text { Wavelength } \\
(\mathbf{n m})\end{array}$ & Bandwidth & $\begin{array}{c}\text { Central } \\
\text { Wavelength } \\
(\mathbf{n m})\end{array}$ & $\begin{array}{c}\text { Bandwidth } \\
(\mathbf{n m})\end{array}$ \\
\hline \multirow{4}{*}{$\mathbf{1 0}$} & 2 & 492.4 & 66 & 492.1 & 66 \\
\cline { 2 - 6 } & 3 & 559.8 & 36 & 559 & 36 \\
\cline { 2 - 6 } & 4 & 664.6 & 31 & 664.9 & 31 \\
\cline { 2 - 6 } & 8 & 832.8 & 106 & 832.9 & 106 \\
\hline \multirow{5}{*}{$\mathbf{2 0}$} & 5 & 704.1 & 15 & 703.8 & 16 \\
\cline { 2 - 6 } & 6 & 740.5 & 15 & 739.1 & 15 \\
\cline { 2 - 6 } & 7 & 782.8 & 20 & 779.7 & 20 \\
\cline { 2 - 6 } & $8 \mathrm{a}$ & 864.7 & 21 & 864 & 22 \\
\cline { 2 - 6 } & 11 & 1613.7 & 91 & 1610.4 & 94 \\
\hline \multirow{3}{*}{$\mathbf{6 0}$} & 12 & 2202.4 & 175 & 2185.7 & 185 \\
\hline & 1 & 442.7 & 21 & 442.2 & 21 \\
\hline & 9 & 945.1 & 20 & 943.2 & 21 \\
\hline & 10 & 1373.5 & 31 & 1376.9 & 30 \\
\hline
\end{tabular}


The Sentinel-2 imagery was acquired on dates 22 October 2015, 26 October 2018, and 23 October 2020 in order to classify the land use classification historical and current of shrimp farm cover. The spatial resolution of Sentinel-2 imagery is $10 \times 10 \mathrm{~m}$ was used for colour composites of Bands 8,4 , and 3 to select the training area and classification of land use. Band combination is created by band combining of spectral data to improve a particular land use. A significant advantage of multispectral images is important to detected the difference surface of the area by the spectral of band combination. Band 8 (Near InfraRed) is very important in terms of ecological monitoring, since the Near InfraRed is the spectrum reflected by the water present in plants. False colour composite of Bands (RGB 8,4,3) was used for classified the vegetation appear red color and water bodies or shrimp farm with appear navy or black color.

\subsection{Image classification from Sentinel-2 imagery}

To survey the land use classes of shrimp farm in the Yang Talad study area, a field survey for collection of training samples and validation were primarily collected from field observations. Data collection by record the land use types including: built-up $(\mathrm{Bu})$, forest $(\mathrm{F})$, water bodies $(\mathrm{W})$, paddy field (Pf), shrimp farm (Sf), and field crop $(\mathrm{Fc})$, respectively.

\subsubsection{Image classification using artificial neural networks (ANN)}

An ANN is a computing system designed based on the structure of the biological neural network of the human nervous system and processes information. The systems of ANN have many layers is also call a multi-layer perceptron with the input layer, a hidden layer, an output layer, each of these layers has a specific purpose. These layers consist of nodes for takes input from the previous layer according to the requirements and transfers them to the next layer show in Fig. 2.

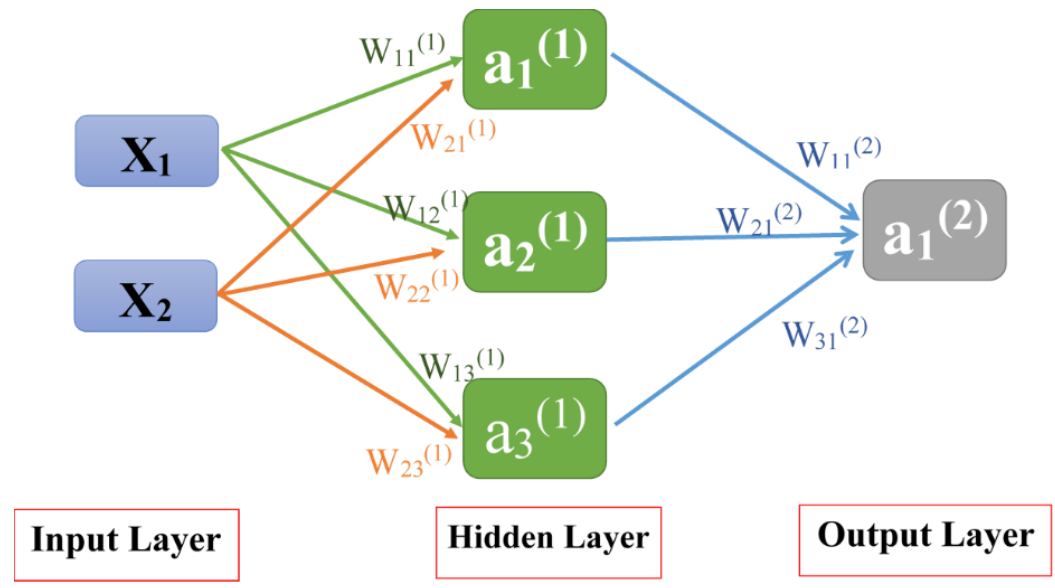

Fig. 2. Structure of a neural network.

The input nodes receive data in a format that can be expressed as numbers. The data is presented as the activation value, where each node receives a number. This data is passed to the network, depending on the strength of the connection (weight). These weights to calculate the weighted sum of inputs and applying an activation function (sigmoid, unit step, linear, etc.) in hidden layer to generate data their output layer. The several ANN models have been applied in land use classification such as Hopfield network, self-organizing competition, radial basis function, multilayer perception, 
and multilayer perception with back propagation (Mas \& Flore, 2008; Xiong et al., 2008; Shrestha et al., 2012). This paper used standard backpropagation for the classifier of land use classes. The error backpropagation was used for back propagated through the network and weight adjustment using a recursive method.

\subsubsection{Land use Classification Types}

Land use classes of the paper were categorized into six land types: built-up (Bu), forest (F), water bodies (W), paddy field (Pf), shrimp farm ( $\mathrm{Sf}$ ), and field crop (Fc) using the ANN classifiers with the regions of interest (ROI) for the training samples of land use classes. The training polygons or ROI was selected as represented of each class in the satellite imagery by digitized on the image based on the prior knowledge of the field surveyed and visual interpretation. The accuracy assessment of this paper using confusion matrices base on binomial probability theory with the desired level of confidence of 85 percent. The 300 samples of the reference point evaluate the classification procedure by using overall accuracy and the kappa coefficient.

\subsubsection{Land use change detection}

The percentage of land use change from the classification map from the map 2015, 2018, and 2020 in the study area. The process to identify the difference of classification map between map 2015 - 2018, and 2018 - 2020 was used the change detection technique. The various technique of change detection techniques has been applied to the monitoring of land use change including image differencing (Lu et al., 2004; Panuju et al.,2020), principal component analysis (Lu et al., 2004; Panuju et al.,2020), and change vector analysis (Lu et al., 2004; Panuju et al.,2020; Sangpradid, 2018). This paper used the image differencing technique was performed to classification the map by subtracts the first date image from a second date image on the digital image value between pixel by pixel.

\section{RESULTS}

\subsection{The result of land use classification}

The results of land use classification map for the years 2015, 2018, and 2020 as shown in Fig. 3, 4, and 5, respectively. The area of the land use classifications from the ANN technique shown the percentage values of an area shown in Table. 2. The land use classes for the year 2015 in this table show that the area cover by built-up was $2.16 \%$, forest was $12.64 \%$, water bodies was $1.93 \%$, paddy field was $1.71 \%$, field crop was $79.88 \%$, and shrimp farm was $1.67 \%$.

Table 2.

The areas and percentage values of $\mathrm{LU}$ classes for the years 2015, 2018, and 2020.

\begin{tabular}{|c|c|c|c|c|c|c|}
\hline \multirow{2}{*}{ Classes } & \multicolumn{2}{|c|}{$\mathbf{2 0 1 5}$} & \multicolumn{2}{c|}{$\mathbf{2 0 1 8}$} & \multicolumn{2}{c|}{$\mathbf{2 0 2 0}$} \\
\cline { 2 - 7 } & sq.km & \% & sq.km & \% & sq.km & \% \\
\hline built-up & 15.00 & 2.16 & 15.71 & 2.26 & 20.99 & 3.03 \\
\hline forest & 87.69 & 12.64 & 65.35 & 9.42 & 59.88 & 8.63 \\
\hline water bodies & 13.42 & 1.93 & 12.88 & 1.86 & 12.93 & 1.86 \\
\hline paddy field & 11.85 & 1.71 & 5.76 & 0.83 & 13.70 & 1.98 \\
\hline field crop & 554.03 & 79.88 & 579.85 & 83.61 & 567.59 & 81.84 \\
\hline shrimp farm & 11.55 & 1.67 & 14.01 & 2.02 & 18.45 & 2.66 \\
\hline
\end{tabular}


The land use classes for the year 2018 show that the area cover by built-up was $2.26 \%$, forest was $9.42 \%$, water bodies was $1.86 \%$, paddy field was $0.83 \%$, field crop was $83.61 \%$, and shrimp farm was $2.02 \%$. The land use classes for the year 2020 show that the area cover by built-up was $3.03 \%$, forest was $8.63 \%$, water bodies was $1.86 \%$, paddy field was $1.98 \%$, field crop was $81.84 \%$, and shrimp farm was $2.66 \%$. The accuracy assessment of land use classified technique using the confusion matrices and kappa coefficient were used the 300 points of randomly by the stratified sampling methods. The overall accuracy and the kappa coefficient as shown in Table 3,4, and 5.

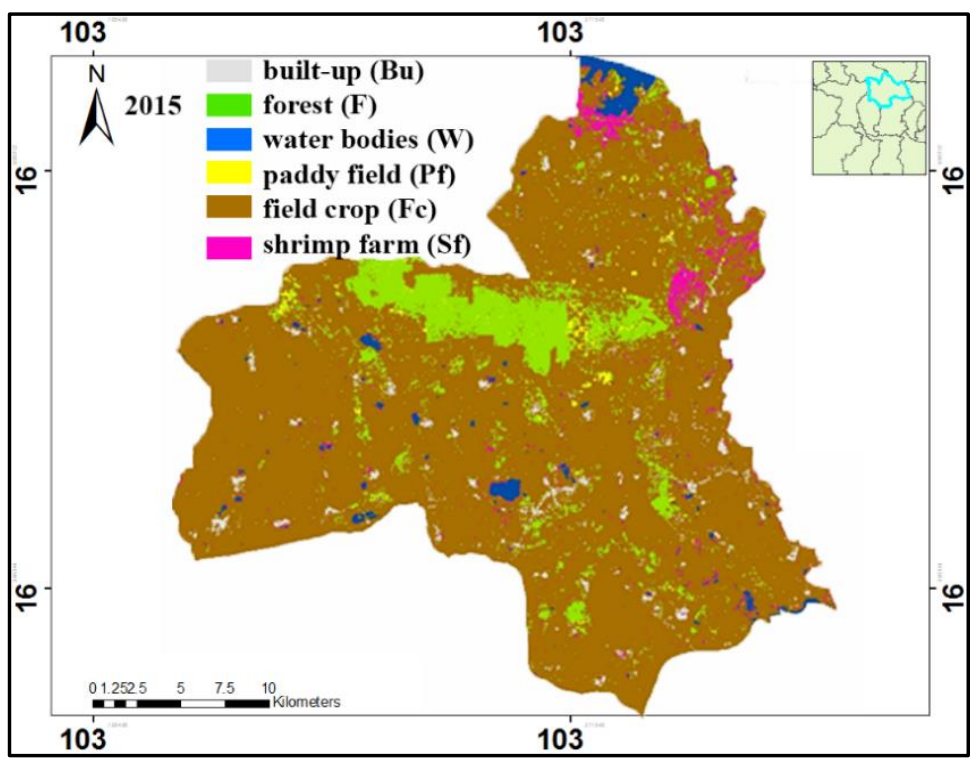

Fig. 3. The land use classes map for the years 2015 of the Yang Talad, Kalasin province, Thailand.

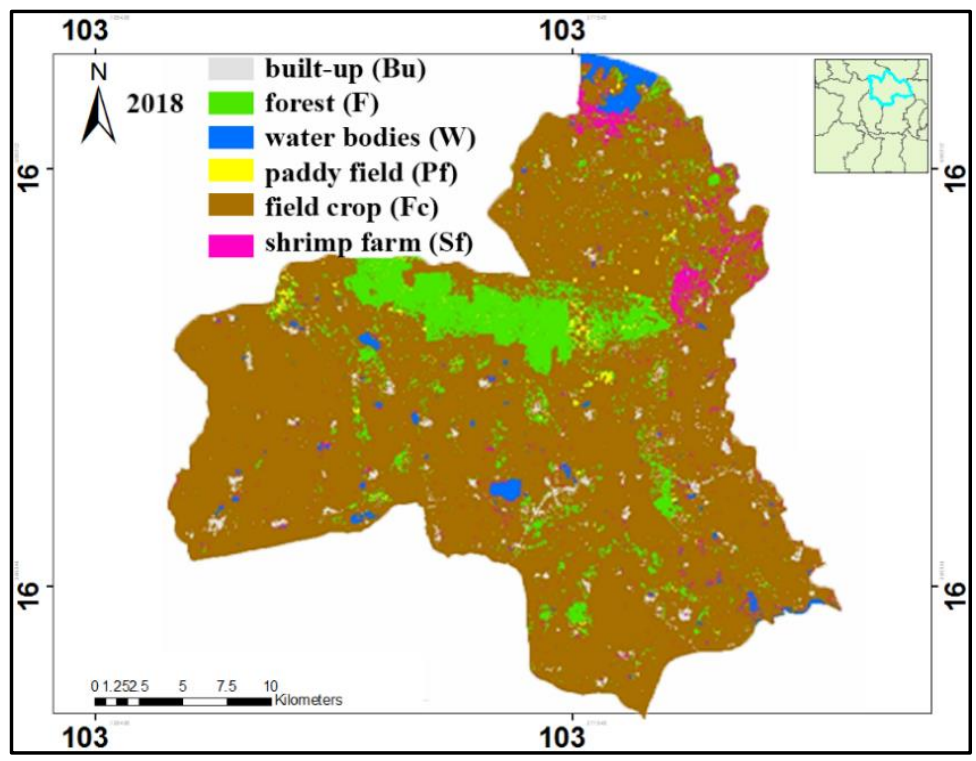

Fig. 4. The land use classes map for the years 2018 of the Yang Talad, Kalasin province, Thailand. 


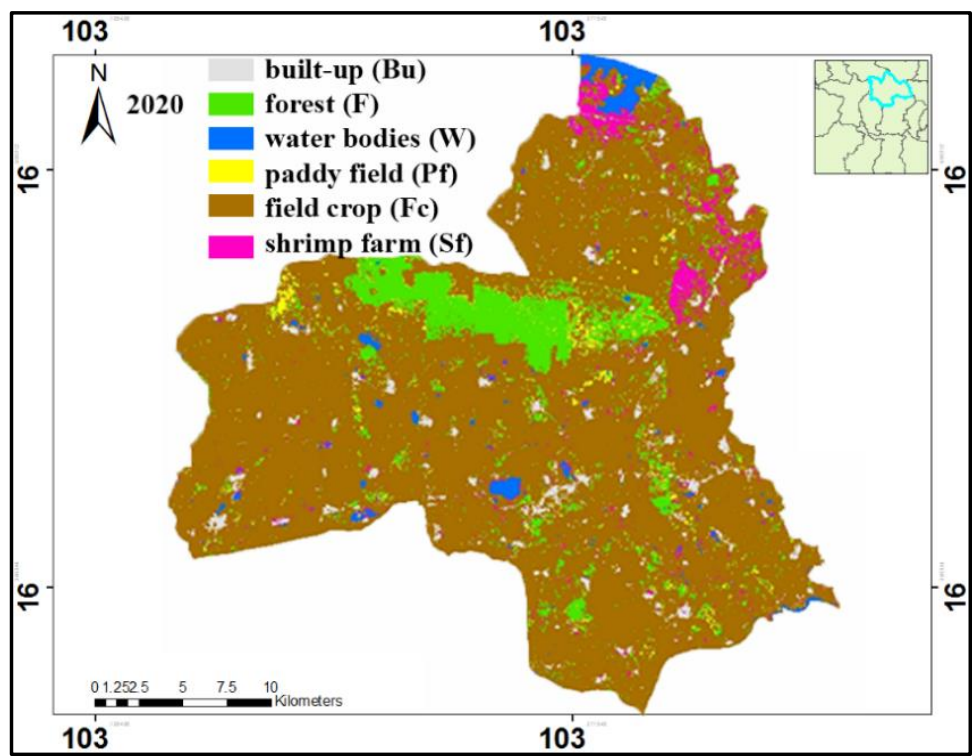

Fig. 5. The land use classes map for the years 2020 of the Yang Talad, Kalasin province, Thailand.

Table 3.

Confusion matrices and kappa coefficient of land use classified for the years 2015.

\begin{tabular}{|c|c|c|c|c|c|c|c|}
\hline \multirow{2}{*}{ Classes } & \multicolumn{6}{|c|}{ Reference data } & \multirow{2}{*}{ tota } \\
\hline & Bu & $\mathbf{F}$ & $\mathbf{W b}$ & $\mathbf{P f}$ & Fc & Sf & \\
\hline $\mathrm{Bu}$ & 47 & 0 & 0 & 0 & 2 & 0 & 49 \\
\hline $\mathrm{F}$ & 0 & 46 & 0 & 2 & 0 & 1 & 49 \\
\hline $\mathrm{Wb}$ & 0 & 0 & 47 & 0 & 0 & 0 & 47 \\
\hline $\mathrm{Pf}$ & 0 & 4 & 0 & 46 & 0 & 1 & 51 \\
\hline $\mathrm{Fc}$ & 3 & 0 & 0 & 2 & 47 & 2 & 54 \\
\hline $\mathrm{Sf}$ & 0 & 0 & 3 & 0 & 1 & 46 & 50 \\
\hline total & 50 & 50 & 50 & 50 & 50 & 50 & 300 \\
\hline
\end{tabular}

Table 4.

Confusion matrices and kappa coefficient of land use classified for the years 2018.

\begin{tabular}{|c|c|c|c|c|c|c|c|}
\hline \multirow{2}{*}{ Classes } & \multicolumn{6}{|c|}{ Reference data } & \multirow{2}{*}{ tota } \\
\hline & Bu & $\mathbf{F}$ & $\mathbf{W b}$ & Pf & Fc & Sf & \\
\hline $\mathrm{Bu}$ & 47 & 0 & 1 & 0 & 0 & 0 & 48 \\
\hline $\mathrm{F}$ & 0 & 46 & 0 & 3 & 0 & 1 & 50 \\
\hline $\mathrm{Wb}$ & 1 & 0 & 46 & 0 & 2 & 0 & 49 \\
\hline Pf & 0 & 4 & 0 & 45 & 0 & 1 & 50 \\
\hline $\mathrm{Fc}$ & 2 & 0 & 1 & 2 & 47 & 2 & 54 \\
\hline Sf & 0 & 0 & 2 & 0 & 1 & 46 & 49 \\
\hline total & 50 & 50 & 50 & 50 & 50 & 50 & 300 \\
\hline
\end{tabular}


The accuracy assessment of land use classification using the confusion matrices for year 2015 show that the overall accuracy was $93 \%$ and the kappa coefficient was 0.916 as shown in Table 3 . The accuracy assessment of land use classification using the confusion matrices for year 2018 show that the overall accuracy was $92.33 \%$ and the kappa coefficient was 0.910 as shown in Table 4. The accuracy assessment of land use classification using the confusion matrices for year 2020 show that the overall accuracy was $91.66 \%$ and the kappa coefficient was 0.90 as shown in Table 5.

Table 5.

Confusion matrices and kappa coefficient of land use classified for the years 2020.

\begin{tabular}{|c|c|c|c|c|c|c|c|}
\hline \multirow{2}{*}{ Classes } & \multicolumn{6}{|c|}{ Reference data } & \multirow{2}{*}{ total } \\
\hline & $\mathbf{B u}$ & $\mathbf{F}$ & $\mathbf{W b}$ & Pf & Fc & Sf & \\
\hline $\mathrm{Bu}$ & 45 & 0 & 0 & 0 & 1 & 1 & 47 \\
\hline $\mathrm{F}$ & 0 & 47 & 0 & 1 & 0 & 0 & 48 \\
\hline $\mathrm{Wb}$ & 0 & 1 & 46 & 1 & 0 & 2 & 50 \\
\hline Pf & 2 & 1 & 0 & 46 & 2 & 0 & 51 \\
\hline $\mathrm{Fc}$ & 3 & 1 & 1 & 1 & 46 & 2 & 54 \\
\hline Sf & 0 & 0 & 3 & 1 & 1 & 45 & 50 \\
\hline total & 50 & 50 & 50 & 50 & 50 & 50 & 300 \\
\hline
\end{tabular}

\subsection{The result of Land use change detection}

The results of the land use change detection were performed by image differencing method show that in Table 6. The area of land use change between year 2015 and 2018 show that built-up area increased was $4.67 \%$, forest area decreased was $25.48 \%$, water bodies decreased was $3.99 \%$, paddy field decreased was $51.44 \%$, field crop increased was $4.66 \%$, and shrimp farm increased was $21.28 \%$. The area of land use change between year 2018 and 2020 show that built-up area increased was $33.66 \%$, forest area decreased was $8.37 \%$, water bodies increased was $0.36 \%$, paddy field increased was $138.05 \%$, field crop decreased was $2.11 \%$, and shrimp farm increased was $31.74 \%$. The area of land use change between year 2015 and 2020 show that built-up area increased was $28.52 \%$, forest area decreased was $46.44 \%$, water bodies decreased was $3.79 \%$, paddy field increased was $13.50 \%$, field crop increased was $2.39 \%$, and shrimp farm increased was $37.41 \%$.

The area of land use change detection on years 2015, 2018, and 2020.

Table 6.

\begin{tabular}{|c|c|c|c|c|c|c|}
\hline \multirow{2}{*}{ Classes } & \multicolumn{2}{|c|}{$\begin{array}{c}\text { Chang detection } \\
(\mathbf{2 0 1 5 - 2 0 1 8 )}\end{array}$} & \multicolumn{2}{c|}{$\begin{array}{c}\text { Chang detection } \\
\mathbf{( 2 0 1 8 - 2 0 2 0}\end{array}$} & \multicolumn{2}{c|}{$\begin{array}{c}\text { Chang detection } \\
\text { (2015-2020) }\end{array}$} \\
\cline { 2 - 7 } & sq.km & \% & sq.km & \% & sq.km & \% \\
\hline built-up & 0.70 & 4.67 & 5.29 & 33.66 & 5.99 & 28.52 \\
\hline forest & -22.34 & -25.48 & -5.47 & -8.37 & -27.81 & -46.44 \\
\hline water bodies & -0.54 & -3.99 & 0.05 & 0.36 & -0.49 & -3.79 \\
\hline paddy field & -6.10 & -51.44 & 7.95 & 138.05 & 1.85 & 13.50 \\
\hline field crop & 25.81 & 4.66 & -12.26 & -2.11 & 13.56 & 2.39 \\
\hline shrimp farm & 2.46 & 21.28 & 4.45 & 31.74 & 6.90 & 37.41 \\
\hline
\end{tabular}




\section{DISCUSSION AND CONCLUSIONS}

As the result of the land use classification for the year 2015, 2018, and 2020 found that the area of Yang Talad district about $80 \%$ cover by field crop area. Meanwhile, the shrimp farm area covers about $2.66 \%$. The classification accuracy of the ANN technique shows that the overall accuracy and kappa coefficient higher than $91.66 \%$ and 0.90 , respectively. The results accuracy assessment by the producer's accuracy of the ANN technique for the year 2015 show that built-up was $94 \%$, forest was $92 \%$, water bodies was $94 \%$, paddy field was $92 \%$, field crop was $94 \%$, and shrimp farm was $92 \%$. The producer's accuracy of the ANN technique for the year 2018 show that built-up was $94 \%$, forest was $92 \%$, water bodies was $92 \%$, paddy field was $90 \%$, field crop was $94 \%$, and shrimp farm was $92 \%$. The producer's accuracy of the ANN technique for the year 2020 show that built-up was $90 \%$, forest was $94 \%$, water bodies was $92 \%$, paddy field was $92 \%$, field crop was $92 \%$, and shrimp farm was $90 \%$. The results of land use classes map of the year 2015, 2018, and 2020 show that the pink color of land use maps show the area of shrimp farm compared with the surveyed and visual interpretation was the accurate with the shrimp farm area existing.

In addition, the comparison of the results of the land use classify show with similar research such as Dorber et al. (2020) presented the remote sensing can be use to provide spatially explicit land-use change information of shrimp aquaculture. The results of accuracy assessment show that the accuracy of the spatial resolution of Setinel-2 similar with Costantino et al. (2020). The land use change detection show that forest area decreased throughout between year 2015 to 2020 was $46.44 \%$. The land use of built-up, paddy field, and shrimp farm increased throughout between year 2015 to 2020 . The shrimp farm between year 2015 to 2020 to increasing trend of related with the shrimp production was the high demand for the popular in the global market in Thailand (Thai Shrimp Association. (2019). The shrimp farm area increased was $37.41 \%$. Furthermore, the results of land use change of shrimp farm can be used for predicting the future land use by using the prediction model such as land change modeler or Ca-Markov model.

\section{ACKNOWLEDGMENT}

This paper was supported by Faculty of Informatics, Mahasarakham University and Research unit of Geo-informatics for Local Development, and Faculty of Management Sciences, Valaya Alongkorn Rajabhat University Under the Royal Patronage.

\section{REFERENCES}

Ahmad, A. (2013). Comparative analysis of supervised and unsupervised classification on multispectral data. Applied Mathematical Sciences, 7(74), 3681 - 3694.

Alonso-Pereza, F., Ruiz-Lunab, A., Turnerc, J., Berlanga-Roblesb, C.A., \& Mitchenson-Jacobc, G. (2003). Land cover changes and impact of shrimp aquaculture on the landscape in the Ceuta coastal lagoon system, Sinaloa, Mexico. Ocean \& Coastal Management, 46,583-600.

Costanino, D., Pepe, M., Dardanelli, G., Baiocchi, V. (2020). Using optical satellite and aerial imagery for automatic coastline mapping. Geographia Technica, 15(2), 171-190.

Dorber, M., Verones, F., Nakaoka, M., Sudo, K. (2020). Can we locate shrimp aquaculture areas from space? A case study for Thailand. Remote Sensing Applications: Society and Environment, 20, 1-9.

Erbek, F. S., Özkan, C., \& Taberner, M. (2004). Comparison of maximum likelihood classification method with supervised artificial neural network algorithms for land use activities. International Journal of Remote Sensing, 25(9), 1733-1748.

Foody, G.M., McCulloch, M.B., \& Yates, W.B. (1995). Classification of remote sensed data by artificial neural networks: Issues Related to training Data Characteristics. Photogrammetric Engineering \& Remote Sensing, 61(4), 391-401. 
Ge, G., Shi, Z., Yang, X., Hao, Y. (2020). Land use/cover classification in an arid desert-oasis mosaic landscape of China using remote sensed imagery: Performance assessment of four machine learning algorithms. Global Ecology and Conservation, 22, 1-9.

Jomsrekrayom, N., Meena, P., Laosuwan, T. (2021). Spatiotemporal Analysis of Vegetation Drought Variability in the Middle of the Northeast Region of Thailand Using TERRA/MODIS Satellite Data. Geographia Technica, 16 (Special Issue), 70-81.

Kovacs, K.D. (2019). Evaluation of burned areas with Sentinel-2 using snap: the case of Kineta and Mati, Greece, july 2018. Geographia Technica, 14(2), 20-38.

Lu, D., Mausel, P., Brondizio, E., \& Moran, E. (2004). Change detection techniques. International Journal of Remote Sensing, 25(12), 2365-2407.

Lu, D., \& Weng, Q. (2007). A survey of image classification methods and techniques for improving classification performance. International Journal of Remote Sensing, 28, 823-870.

Mahmon, N.A., \& Ya'acob, N. (2014). A review on classification of satellite image using artificial neural network (ANN). IEEE 5th Control and System Graduate Research Colloquium, Aug. 11 - 12, UiTM, Shah Alam, Malaysia.

Mas, J.F., \& Flores, J.J. (2008). The application of artificial neural networks to the analysis of remotely sensed data. International Journal of Remote Sensing, 29(3),617-663.

Maung, W.S., \& Sasaki, J. (2021). Assessing the natural recovery of mangroves after human disturbance using neural network classification and Sentinel-2i in Wunbaik Mangrove Forest, Myanmar. Remote Sensing, 13,52 .

Migas-Mazur, R., Kycko, M., Zwijacz-Kozica, T., Zagajewski, B. (2021). Assessment of Sentinel-2 images, support vector machines and change detection algorithms for bark beetle outbreaks mapping in the Tatra mountains. Remote sensing, 12, 3314.

Ottinger, M., Clauss, K., \& Kuenxer, C. (2017). Large-scale assessment of coastal aquaculture ponds with Sentinel-1 time series data . Remote Sensing, 9, 440;

Panalekar, S.M., Thomson, A., Verhoef, A., Humphries, D.J., Reynolds, C.K. (2021). Assessing suitability of Sentinel-2 bands for monitoring of nutrient concentration of pastures with a rang of species compositions. Agronomy, 11,1661.

Panuju, D.R., Paull, D.J., Griffin, A.L. (2018). Change detection techniques based on multispectral images for investigating land cover dynamics. Remote Sensing. 2020, 12, 1781.

Pradabmook. P., Laosuwan, T. (2021). The integration of geo-informatics technology with Universal Soil Loss Equation to analyze areas prone to soil erosion in Nan Province. ARPN Journal of Engineering and Applied Science, 18(8), 823-830.

Rajitha, K., Mukherjee, C.K., \& Chandran R.V. (2007). Applications of remote sensing and GIS for sustainable management of shrimp culture in India. Aquacultural Engineering, 36, 1-17.

Santaga, F.S., Agnelli, A., Leccese, A., Vizzari, M. (2021). Using Sentinel-2 for simplifying soil sampling and mapping: two case studies in Umbria, Italy. Remote sensing, 13, 3379.

Sangpradid, S. (2018). Change vector analysis using integrated vegetation indices for land cover change detection. International Journal of Geoinformatics, 14 (4), 71-77.

Shrestha, S., Bochenek, Z., \& Smith, C. (2012). A comparison of supervised classification techniques for land cover classification for the Warsaw Region using SPOT 4 imagery. First Sentinel-2 Preparatory Symposium, Frascati, Italy, 23-27 April 2012, ESA SP-707, July 2012.

Stiller, D., Ottinger, M., \& Leinenkugel, P. (2019). Spatio-temporal patterns of coastal aquaculture derived from Sentinel-1 time series data and the full Landsat archive. Remote sensing, 11, 1707.

Thai Shrimp Association. (2019). Shrimp situation in the Thailand of 2020. http://inlandfisheries.go.th/images/pdf/sT1.pdf (in Thai).

Toosi, N.B., Soffianian, A.R., Fakheran, S., Pourmanafi, S., Ginzler, C., \& Waser, L.T. (2019). Comparing different classification algorithms for monitoring mangrove cover changes in southern Iran. Global Ecology and Conservation, 19, 1-16.

Toshniwal, M. (2005). Satellite image classification using neural networks. 3rd International Conference: Sciences of Electronic, Technologies of Information and Telecommunications, March 27-31, TUNISIA.

Urban, M., Schellenberg, K., Morhenthal, T., Dubois, C., Hirner, A., Gessner, U., Mogonong, B., Zhang, Z, Baade, J., Collett, A., Schmullius, C. (2021). Using Sentinel-1 and Sentinel-2 time series for slangbos mapping in the Free State Province, South Africa. Remote sensing, 13, 3342. 
USGS EROS Center.2015. USGS EROS Archive - Sentinel-2. https://www.usgs.gov/centers/eros/science/usgseros-archive-sentinel-2?qt-science_center_objects=0\#qt-science_center_objects.

Varghese, D., Radulovic, M., Stojkovic, S., Crnojevic, V. (2021). Reviewing the potential of Sentinel-2 in assessing the drought. Remote sensing, 13, 3355.

Vanderhoof, M.K., Hawbaker, T.J., Teske, C, Ku, A., Noble, J. (2021). Mapping wetland burned area from Sentinel-2 acros the southeastern United State and its contributions relative to Landsat-8 (2016-2019). Fire, 4, 52.

Xiong,Y., Zhang, Z. \& Chen, F. (2010). Comparison of artificial neural network and support vector machine methods for urban land use/cover classifications from remote sensing images. International Conference on Computer Application and System Modeling (ICCASM 2010), 52-56.

Yaday, P., Kapoor, M. \& Sarma, K. (2010). Land use land cover mapping, change detection and conflict analysis of Nagzira - Navegaonc, centeral India using geospatial technology. International Journal of Remote Sensing and GIS, 1(2), 90-98. 